\title{
Radon transport model into a porous ground layer of finite capacity
}

\author{
Roman Parovik ${ }^{1,2, \star}$ \\ ${ }^{1}$ Institute of Cosmophysical Research and Radio Wave Propagation of the Far Eastern Branch of Russian \\ Academy of Science, 684034, Kamchatskiy kray, Paratunka, Mirnaya str. 7, Russia. \\ ${ }^{2}$ Vitus Bering Kamchatka State University, 683032, Kamchatskiy kray, Petropavlovsk-Kamchatskiy, \\ Pogranichaya str. 4, Russia.
}

\begin{abstract}
The model of radon transfer is considered in a porous ground layer of finite power. With the help of the Laplace integral transformation, a numerical solution of this model is obtained which is based on the construction of a generalized quadrature formula of the highest degree of accuracy for the transition to the original - the function of solving this problem. The calculated curves are constructed and investigated depending on the diffusion and advection coefficients. The work was a mathematical model that describes the effect of the sliding attachment (stick-slip), taking into account hereditarity. This model can be regarded as a mechanical model of earthquake preparation. For such a model was proposed explicit finite- difference scheme, on which were built the waveform and phase trajectories hereditarity effect of stick-slip.
\end{abstract}

\section{Introduction}

Mathematical modeling of radon $\left({ }^{222} \mathrm{Rn}\right)$ transfer processes is an actual problem due to various applications. One of such applications is the study of precursors of strong earthquakes with the aim of their possible prediction $[1,2]$. In these papers, it is shown that radon is an indicator of the stress-strain state of the geomedium and its responses are observed into the field of subground radon in the form of various anomalies.

Mathematical modeling of radon transfer processes is considered within the framework of the emanation method, which is described in detail in $[3,4]$. As a rule, the main contribution to the transport mechanism of $\mathrm{Rn}$ is made by the diffusion and advection processes, however, the migration capacity of $\mathrm{Rn}$ is influenced by meteorological conditions, groundwater discharge, effusion, geological parameters and properties of the geomedium, etc. $[3,5]$. Therefore, the mathematical model of the transfer of $\mathrm{Rn}$ in the geo-environment is adopted with some assumptions.

In this paper, we will assume that the non-stationary transfer of Rn occurs in a homogeneous layer of porous ground only due to the diffusion-advection mechanism, and we also assume that the influence of meteorological conditions on the transport process $\mathrm{Rn}$ is insignificant and can be neglected. Consider the following problems.

^e-mail: parovik@ikir.ru 


\section{Statement of the problem and methods of solution}

The first we consider the problem in the case when the nonstationary transfer of Rn occurs in a homogeneous layer of porous ground with infinite power.

Problem 1. There is an emanating homogeneous layer of ground of infinite power with free emanation $\mathrm{Rn}$. It is required to find the diffusion-advective distribution of radon volume activity (VA Rn) $A(z, t)$ in time $t$ and spatial coordinate $z$ [3].

Mathematical model of this problem:

$$
\begin{aligned}
& \frac{\partial A(z, t)}{\partial t}=D \frac{\partial^{2} A(z, t)}{\partial z^{2}}+v \frac{\partial A(z, t)}{\partial z}-\lambda\left(A(z, t)-A_{\infty}\right), \\
& \text { 1) } \left.z=0, A=0,2) z \rightarrow \infty, A=A_{\infty}, 3\right) t=0, A=A_{\infty},
\end{aligned}
$$

where $D$ - diffusion coefficient $\mathrm{Rn}$ into the ground, $\mathrm{m}^{2} / \mathrm{s} ; v$ - Rn advection speed into the ground, $\mathrm{m} / \mathrm{s}$; $\lambda$ - decay constant Rn, $1 / \mathrm{c} ; A_{\infty}={ }_{e m} A_{R a} \rho_{s}(1-\eta)$ - volume activity of radon, which is in radioactive equilibrium with radium $\left({ }^{226} \mathrm{Ra}\right)$ to a certain depth; $K_{e m}$ - emanation Coefficient $\mathrm{Rn}$, in relative units; $A_{R a}$ - Specific activity ${ }^{226} \mathrm{Ra}, \mathrm{Bq} / \mathrm{kg} ; \rho_{s}$-density of solid ground particles, $\mathrm{kg} / \mathrm{m}^{3} ; \eta$ - porosity, in relative units.

Using the integral Laplace transform and the initial condition 3, problem (1) - (2) can be written for the image $F(z, p)$ as follows:

$$
\begin{gathered}
D \frac{d^{2} F(z, p)}{d z^{2}}+v \frac{d F(z, p)}{d z}-(p+\lambda) F(z, p)-\frac{A_{\infty}(p+\lambda)}{p}=0, \\
\text { 1) } z=0, F=0,2) z \rightarrow \infty, F=\frac{A_{\infty}}{p} .
\end{gathered}
$$

The solution of equation (1) can be written:

$$
F(z, p)=C_{1} \exp \left(z\left[-\frac{v}{2 D}+\sqrt{\frac{\lambda+p}{D}+\frac{v^{2}}{4 D^{2}}}\right]\right)+C_{2} \exp \left(-z\left[\frac{v}{2 D}+\sqrt{\frac{\lambda+p}{D}+\frac{v^{2}}{4 D^{2}}}\right]\right)+\frac{A_{\infty}}{p}
$$

where $C_{1}, C_{2}$ - constants of integration, which are determined from the conditions (4). Taking account this condition, solution (5) has the form:

$$
F(z, p)=\frac{A_{\infty}}{p}\left(1-\exp \left(-z\left[\frac{v}{2 D}+\sqrt{\frac{\lambda+p}{D}+\frac{v^{2}}{4 D^{2}}}\right]\right),\right.
$$

Turning to the original for (6), using the reference [6], we obtain:

$$
\begin{gathered}
A(z, t)=A_{\infty}\left(1-\frac{1}{2}\left(e^{z^{-}} \operatorname{erfc}\left(u^{-}\right)+e^{z^{+}} \operatorname{erfc}\left(u^{+}\right)\right)\right) \\
z^{-}=z\left(\frac{v}{2 D}-\sqrt{\frac{\lambda}{D}+\left(\frac{v}{2 D}\right)^{2}}\right), z^{+}=z\left(\frac{v}{2 D}+\sqrt{\frac{\lambda}{D}+\left(\frac{v}{2 D}\right)^{2}}\right), \\
u^{-}=\frac{z}{2 \sqrt{D t}}-\sqrt{\left(\frac{v^{2}}{4 D}+\lambda\right) t, u^{+}}=\frac{z}{2 \sqrt{D t}}+\sqrt{\left(\frac{v^{2}}{4 D}+\lambda\right) t} \\
\operatorname{erfc}(z)=1-\operatorname{erf}(z), \operatorname{erf}(z)=\frac{2}{\sqrt{\pi}} \int_{0}^{z} e^{-z^{2}} d z .
\end{gathered}
$$


Solution (7) is given and studied in [7], but for a two-layer ground-atmosphere model. The case $v=0$ is given in [3].

Noted, that in the case of transfer of Rn in a layer of infinite power, due to the second condition (4), the problem of image reversal is simplified. Let us consider a somewhat different problem.

Problem 2. There is an emanating homogeneous layer of ground with a thickness $l$ of free emanation. It is required to find the diffusion-advective distribution of radon volume activity $A(z, t)$ in time and space.

$$
\begin{gathered}
\frac{\partial A(z, t)}{\partial t}=D \frac{\partial^{2} A(z, t)}{\partial z^{2}}+v \frac{\partial A(z, t)}{\partial z}-\lambda\left(A(z, t)-A_{\infty}\right), 0<z<l . \\
\text { 1) } \left.z=0, A=0,2) z=l, A=A_{\infty}, 3\right) t=0, A=A_{\infty} .
\end{gathered}
$$

or into the image $F(z, p)$ :

$$
\begin{gathered}
D \frac{d^{2} F(z, p)}{d z^{2}}+v \frac{d F(z, p)}{d z}-(p+\lambda) F(z, p)-\frac{A_{\infty}(p+\lambda)}{p}=0, \\
\text { 1) } z=0, F=0,2) z=l, F=\frac{A_{\infty}}{p} .
\end{gathered}
$$

The solution of equation (10) coincides with the solution of (3), and, taking into account conditions (11), it can be written as:

$$
F(z, p)=\frac{A_{\infty}}{p}\left(1+\frac{\exp \left(-\frac{z v}{2 D}\right) \sinh \left((z-l) \sqrt{\frac{\lambda+p}{D}+\frac{v^{2}}{4 D^{2}}}\right)}{\sinh \left(l \sqrt{\frac{\lambda+p}{D}+\frac{v^{2}}{4 D^{2}}}\right)}\right),
$$

$\sinh (z)=\frac{\exp (z)-\exp (-z)}{2}-$ hyperbolic sine.

We note the solution for the image (12) in the limit $l \rightarrow \infty$ tends to the solution for the image (6). For the image (12), there is no tabular transition to the original, even if it can be reduced to tabular form, the original will be expressed in terms of integrals from the theta-function [6], which makes it difficult to visualize the solution.

For the inversion (12), we use the numerical method for constructing the generalized quadrature formula of the highest degree of accuracy (GQFHDA), proposed in [8]. The GQFHDA method can be written as follows for the inversion formula:

$$
f(t)=\frac{1}{2 \pi i} \int_{c-i \infty}^{c+i \infty} F(p) e^{p t} d p=\frac{t^{s-1}}{2 \pi i} \int_{c-i \infty}^{c+i \infty} p^{-s} \varphi_{s}(p / t) e^{p} d p, c>0,
$$

a quadrature formula of the form is constructed:

$$
\frac{t^{s-1}}{2 \pi i} \int_{c-i \infty}^{c+i \infty} p^{-s} \varphi_{s}(p) e^{p} d p \approx \sum_{k=1}^{n} A_{k} \varphi_{s}\left(p_{k}\right)
$$

$A_{k}, p_{k}$ - coefficients and nodes of the quadrature formula, $\varphi_{s}(p)=p^{s} F(p)$. Next, we introduce a positive number $a$. Region of regularity of the function $\varphi_{s}(p)$ we choose any pair wise distinct points 
$p_{k}, k=1, \ldots, n$ and we require that the quadrature formula (13) is exact for the function $\varphi_{s}(p)=$ $p^{-a m}, m=0,1, \ldots, n-1$, which is equivalent to the fulfillment of the relations:

$$
\sum_{k=1}^{n} A_{k} p_{k}^{-a m}=\frac{1}{\Gamma(s+a m)}, m=0,1, \ldots, n-1
$$

Note that the numbers $p_{k}^{-a}$ are the roots of the polynomial $\omega_{n}(x)=\prod_{k=1}^{n}\left(x-p_{k}^{-a}\right)$ which are uniquely determined by virtue of orthogonality:

$$
\frac{t^{s-1}}{2 \pi i} \int_{c-i \infty}^{c+i \infty} p^{-s} \varphi_{n}\left(p^{-a}\right) p^{-a m} d p=0, m=0,1, \ldots, n-1 .
$$

For example, if the polynomial $\omega_{n}(x)$ is written as: $\omega_{n}(x)=x^{n}+b_{1} x^{n-1}+\ldots+b_{n}$,

Then the orthogonality condition with respect to the coefficients is equivalent to the system of equations:

$$
\frac{b_{1}}{\Gamma(s+(n+k-1) a)}+\ldots+\frac{b_{n}}{\Gamma(s+k a)}=-\frac{1}{\Gamma(s+(n+k) a)}, k=0,1, \ldots, n-1 .
$$

Noted that the polynomial $\omega_{n}(x)$ exists and is uniquely determined. Algorithm for building GQFHDA contains the following stages:

1. the calculation of the coefficients of the equations systems (16) with respect to unknowns $b_{k}$ and the solution of this system;

2. finding the nodes $p_{k}$ of the quadrature formula from equation (15): $\omega_{n}\left(p_{k}^{-a}\right)=p_{k}^{-a n}+b_{1} p_{k}^{-a(n-1)}+$ $\ldots+b_{n}=0$;

3. finding the coefficients $A_{k}$ of the quadrature formula from the conditions (14). In [8] a theorem is proved whose result is an estimate for the error $\varepsilon_{n}\left(t^{a}\right)$ of the GQFHDA for any $t>0$ :

$$
\begin{gathered}
\left|\varepsilon_{n}\left(t^{a}\right)\right| \leq M \sigma_{n}\left(t^{a}, \rho\right), M=\left(\frac{1}{2 \pi i} \int_{0}^{2 \pi}\left|P_{a s}(1+\rho \exp (i \theta))\right|^{2} d \theta\right)^{1 / 2}, P_{a s}=\varphi_{s}\left(t^{-1 / a}\right), \\
\sigma_{n}\left(t^{a}, \rho\right)=\left(\sum_{m=2 n}^{\infty}\left|\sum_{j=2 n}^{m}\left(\begin{array}{c}
m \\
j
\end{array}\right) \frac{(-1)^{j}}{\Gamma(s+a j)}-\sum_{k=1}^{n} A_{k}\left(1-p_{k}^{-a}\right)^{m}\right|^{2}\left(\frac{t^{a}}{\rho}\right)^{2 m}\right)^{1 / 2}, t^{a}<\rho \leq t^{a}+r .
\end{gathered}
$$

$r$ - radius of a circle

\section{Results of modeling}

Consider the solution of problem 2 depending on the different values of the diffusion $D$ and advection $v$ coefficients for the following values of the parameters: $A_{\infty}=1000 \mathrm{~Bq} / \mathrm{m}^{3} ; \lambda=2.1 \cdot 10^{-6} \mathrm{c}^{-1} ; l=$ $100 \mathrm{~cm}$.

For the algorithm GQFHDA: $a=0.5, s=-1, m=100, n=20$. 

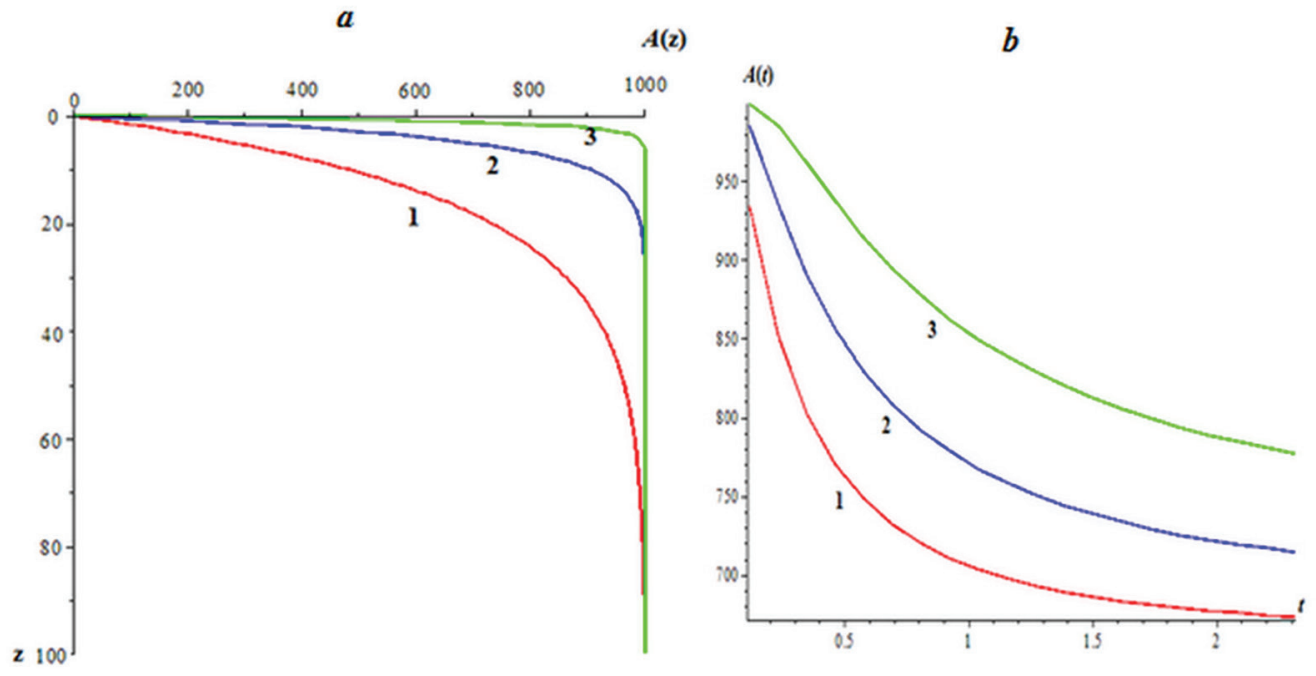

Figure 1. Calculated curves of the distribution of $\mathrm{Rn}$ into the ground in depth: $\boldsymbol{a}) z \in[0,100]$ at a fixed time moment $t=10^{7} \mathrm{c}$ :curve $1-v=10^{-6} \mathrm{~cm} / \mathrm{s}, D=5 \cdot 10^{-4} \mathrm{~cm}^{2} / \mathrm{s} ;$ curve $2-v=5 \cdot 10^{-5} \mathrm{~cm} / \mathrm{s}, \mathrm{cm}^{2} / \mathrm{s} ;$ curve $3-\mathrm{cm} / \mathrm{s}$, $\left.-\mathrm{cm}^{2} / \mathrm{s} ; \boldsymbol{b}\right) z=5 \mathrm{~cm}$ : curve $1-\mathrm{cm} / \mathrm{s}, D=5 \cdot 10^{-4} \mathrm{~cm}^{2} / \mathrm{s}$; curve $2-\mathrm{cm} / \mathrm{s}, D=2.5 \cdot 10^{-4} \mathrm{~cm}^{2} / \mathrm{s}$; Curve $3-\mathrm{cm} / \mathrm{s}$, $\mathrm{cm}^{2} / \mathrm{s}$

In Fig. 1a shows the calculated curves of the distribution of $\mathrm{Rn}$ into the ground in depth, depending on the values of the diffusion and advection coefficients for a fixed time c. It is seen that as the value of the advection coefficient increases, the migration capacity of Rn increases, (curve 3 ). This is manifested by a rapid exit to the background level $A_{\infty}$ at shallow depths .

In Fig. 1b shows the calculated curves of Rn distributions into the ground as a function of time $t \in[0,2.31]$ at the point $z=5 \mathrm{~cm}$. It is seen that as the value of the advection coefficient increases, the concentration of $\mathrm{Rn}$ at a point decreases more rapidly (curve 3), i.e. faster goes to stationary mode.

These results show that taking into account the advective component is important in modeling the migration of $\mathrm{Rn}$ [9]. The diffusion and advection coefficients can be estimated using experimental data [10] or tables [3].

Noted that the error of the GQFHDA method by formula (17) was, which indicates an increased accuracy of the quadrature formula (13).

\section{Conclusion}

In $[11,12]$, using georadar studies, it was established that the registration points have a layered structure, with two or even three layers clearly identified. Each layer has its own physico-geological parameters. Therefore, problem 2 can be generalized to the case of a two-layer or three-layer geomedium. Of course, the consideration of the properties of the geomedium, namely, the in homogeneity, which can be expressed, for example, by fractal properties [13] or a piecewise-constant anisotropic layered structure with inclusions, deserves close attention [14]. Such problems will be solved by numerical methods as in [15]. 


\section{Acknowledgments}

The paper on the order of RFFI grant No. 16-05-00162 "Presentation of strong earthquakes into the field of subground radon in the Petropavlovsk-Kamchatka geodynamic test range".

\section{References}

[1] V.P. Rudakov, J. Geokhim. 9 (1986)

[2] P.P. Firstov , V.P. Rudakov, J. Vulk. i seysm. 6 (2002)

[3] G.F. Novikov Radiometricheskaya razvedka (Leningrad, Nedra, 1989)

[4] R.I. Parovik Matematicheskiye modeli klassicheskoy teorii emanatsionnogo metoda (Petropavlovsk-Kamchatskiy, KamGU im. Vitusa Beringa, 2014)

[5] V.S. Yakovleva, P.M. Nagorsky, A.G. Kondratyeva, N.V. Mishina The influence of meteorological parameters and other factors on soil radon dynamics. Innovative Technologies in Engineering VII International Scientific Practical Conference (Conference Proceedings. National Research Tomsk Polytechnic University. 2016.)

[6] V.A. Ditkin, A.P. Prudnikov Spravochnik po operatsionnomu ischisleniyu (Moskva, Vysshaya shkola, 1965).

[7] R.I. Parovik Vestnik KRAUNTS. Fiz.-mat. nauki 1, 1 (2010)

[8] T.A. Matveyeva Nekotoryye metody obrashcheniya preobrazovaniya Laplasa i ikh prilozheniya (Diss. kand. fiz.-mat. nauk. Sankt-Peterburg. 2003).

[9] P.P. Firstov, R.I. Parovik, V.S. Yakovleva, O.P. Malysheva Svyaz' skorosti advektsii i plotnosti potoka radona s sil'nymi zemletryaseniyami yuzhnoy Kamchatki 2000-2008 gg. Solnechnozemnyye svyazi $i$ predvestniki zemletryaseniy (Dal'nevostochnoye otdeleniye, Institut kosmofizicheskikh issledovaniy i rasprostraneniya radiovoln. 2010).

[10] V.S. Yakovleva Vestnik KRAUNTS. Fiz.-mat. nauki. 8, 1 (2014)

[11] P.P. Firstov, R.I.Parovik, R.R. Akbashev, Ye.O. Makarov Stroyeniye verkhney chasti geologicheskikh razrezov $v$ punktakh monitoringa pochvennogo radona na petropavlovsk-kamchatskom geodinamicheskom poligone. Vulkanizm i svyazannyye s nim protsessy (Materialy regional'noy nauchnoy konferentsii, posvyashchonnoy Dnyu vulkanologa. 2014).

[12] P.P. Firstov, Ye.O. Makarov, S.Yu. Paskar', R.I. Parovik ANRI 4 (87) (2016)

[13] R.I. Parovik, B.M. Shevtsov J. Math. Mod. and Comp. Sim. 2, 2 (2010)

[14] A.R. Nafikova, V.N. Krizskiy Matematicheskoye modelirovaniye protsessov perenosa radona $v$ kusochno-postoyannykh anizotropnykh sloistykh sredakh $s$ vklyucheniyami (Sterlitamak: BashGU, 2016)

[15] V.S. Yakovleva, R.I. Parovik Nukleonika 55, 4 (2010) 